\title{
The Influence of Individual Factors on the University Students Self-efficacy
}

\author{
Yousef Alrashed \\ Self-development Department, Deanship of Preparatory Year and Supporting Studies, Imam Abdulrahman Bin Faisal University, \\ Saudi Arabia
}

Received February 11, 2021; Revised March 12, 2021; Accepted April 22, 2021

\section{Cite This Paper in the following Citation Styles}

(a): [1] Yousef Alrashed, "The Influence of Individual Factors on the University Students Self-efficacy," Universal Journal of Educational Research, Vol. 9, No. 5, pp. 1083 - 1087, 2021. DOI: 10.13189/ujer.2021.090521.

(b): Yousef Alrashed (2021). The Influence of Individual Factors on the University Students Self-efficacy. Universal Journal of Educational Research, 9(5), 1083 - 1087. DOI: 10.13189/ujer.2021.090521.

Copyright $(2021$ by authors, all rights reserved. Authors agree that this article remains permanently open access under the terms of the Creative Commons Attribution License 4.0 International License

\begin{abstract}
Recently, literature indicated self-efficacy as an important factor in educational settings. Previous research claimed that self-efficacy had a significant role in enhancing students learning and its outcomes. However, in Saudi Arabia, university focused on improving students with the necessary skills that foster their future success. The main aim of the present study is to investigate the participants' self-efficacy levels as well as identify the difference level of self-efficacy based on their individual factors such as gender, age, and educational levels. The study was conducted among 63 participants in a government university in Eastern region of Saudi Arabia. Several statistical tests were used such as descriptive statistics, t-test and ANOVA. The study findings revealed that participants had a moderate level of self-efficacy. The findings also reported that the participants had some differences in the mean score of self-efficacy. Furthermore, insignificant differences were reported between students' variables on the self-efficacy level. The finding of this study is hoped to add to literature on students learning and the significant role of self-efficacy towards students' future. Based on the results, implications and recommendations were highlighted.
\end{abstract}

Keywords Self-efficacy, University, Students, Individual Factors

\section{Introduction}

Literature concerning educational environment is extensive and generally motivated researchers to identify the related academic and academic factors which may influence students' success. The studies showed that emotional, social and personal factors play crucial role in the success of students $[1,2,3]$, such as study environment, promotion of achievement, engaging attitude and self-efficacy $[1,2,4]$. Self-efficacy is one of the crucial concepts of the important concepts in self-learning theory which has been defined by Bandura [5], as "the ability used for the description of how to behave and possess skills to do something, that determines whether or not a behavior is conducted. Bandura [6], also described self-efficacy as the degree of efforts exerted for tasks accomplishment and individual mechanism to encounter cognitive, emotional and physical challenges. Self-efficacy is one of the components of the self or personal determinants of self-organized learning, as it includes three determinants or factors which are personal, environmental, and behavioral determinants. The interaction between those determinants is a major constituent of the social cognitive theory of Bandura [7].

Self-efficacy level among students was noted to be declined [8], which can be attributed to the influence of other factors that leads to individuals' behaviors. Other studies revealed that the level of self-efficacy was moderate [9]. In his study [10] investigates the level of academic self-efficacy of university students studying mathematics in Turkey in light of gender and academic year variables. The sample of the study consisted of (244) male and female students. The results showed that the level of academic self-efficacy of the students was moderate. 
Although, studies described the importance of self-efficacy, but only a few examined the concept in educational environment. Thus, it is necessary to enrich the literature by conducting more studies to identify the self-efficacy in the educational settings. This study primarily contributes to literature by examining the level of self-efficacy among students through investigated the level of university student's self-efficacy. This would furnish an understanding of the related significance of the concepts for successful students.

\subsection{Objectives of the Study}

The study aimed at investigating the self-efficacy level among the study respondents. The study objectives are:

- To find out self-efficacy level among Saudi participants.

- To examine the gender differences in terms of their self-efficacy level.

- To determine the age and educational level differences in terms of students' self-efficacy level.

\section{Literature Review}

\subsection{Self-efficacy}

Self-efficacy is an important psychological factor affecting many emotional variables such as perseverance, academic performance and self-confidence [7]. This efficacy is crystallized in capabilities and competencies that can predict the student's level of academic performance [11]. Learners' possession of a high degree of self-efficacy predicts the safety of the educational process and a significant increase in educational outcomes. In addition, possessing this ability is a key to achieving academic and social harmony and hence the ability to face the challenges and problems they may come across [7]. Therefore, students with a low level of self-efficacy need to develop their capabilities in order to face the pressures and difficulties that may affect their academic and social compatibility. Ramadan [12] defines self-efficacy as "the learner's belief in the ability to accomplish a task or group of tasks in light of his abilities, cognitive and motivation capabilities, which enables him to achieve the required level of performance."

Bandura defined self-efficacy as the personal judgment of one's ability to organize and implement a set of actions to achieve a set of goals. Bandura tried to assess its level, generality and power through activities and content. It has also been suggested that believing in one's self-efficacy influence motivation, feelings, and actions significantly [13]. Self-efficacy levels refer to the difficulty of the specific task, while generality is transferring the beliefs of self-efficacy through activities. As for the power of perceived competence, it is measured by how much confident an individual feels when performing a given task [14].

\subsection{The Importance of Self-efficacy}

Developing self-efficacy among all learners of all age levels is one of the imperatives of the current era since self-efficacy crucially helps individuals to deal effectively with different life situations including defending one's rights and doing one's duties. Self-efficacy also entails overcoming different challenges. A high level of self-efficacy is a significant aspect of a socially successful personality. In addition, individuals with high self-efficacy have a greater ability to achieve various personal goals [15]. Self-efficacy is also considered to be one of the basic psychological variables that help guide and elevate individuals' behavior. In addition, it contributes to empowering individuals to control their surrounding environment. It also increases their ability to achieve and reach the highest levels of perfection in performance. Indeed, individuals' perceptions of themselves can help them to develop and grow in a permanent and independent manner [16].

\section{Methodology}

The study follows descriptive design, which is a positive approach adopted in this study, using the quantitative data collection instrument of questionnaire survey. Survey is suitable in gathering information on the participants belief and attitudes and large sample size [3].Prior studies of the same nature have adopted similar method to examine the study variables in the educational settings $[17,18]$. The participants involved in the current study were having higher educational degree and their affiliated linked to Ministry of Education. The study participants comprised of 63 divided into 35 (55.6) male and 28 (44.4\%) female participants. The age includes four categories, 4 participants $6.3 \%$ (30-35 years old); 15 23.8\% (36-40 years); $1727.0 \%$ (41-45 years); and $2742.9 \%$ (above 45 years old). The participants were selected as they were available to the researcher as well as willing to participate in this study. This study was initially collected a permission from the research committee at Imam Abdulrahman bin Faisal university. Afterword, the researcher asked students to voluntarily participate in this study and they were informed about the goal of the study and its period. Then, students were asked to commit to the study as they may benefited from its activities. Agreement was conducted and students completed the self-efficacy data collection.

\subsection{Measurement}

To determine students' self-efficacy, a self-efficacy scale was given to students twice, at the beginning of the study 
and the other one at the end. The instrument utilized in this study was developed based on the previous studies [19,20]. The scale went through several tests of reliability and validity. First, the scale was evaluated by a group of experts, and their comments were taken into considerations. Few changes were highlighted by the referees and necessary changes were done by the researcher. The instrument content validity was confirmed by the experts. The scale allows identifying students' self-efficacy level through answering 40 items which were distributed into five dimensions which are (academic-efficacy 15 items; evaluation self-efficacy 6 items; usage skills 11 items; managing situations 4 items and efficiency 4 items). The self-efficacy scale is a self-report questionnaire with a likert scale ranged from totally incorrect 1 to completely correct 5. Cronbach's alpha value was also obtained to confirm reliability which was 0.921 .

\section{Results}

Data were analyzed using descriptive statistics, t-test and ANOVA test to answer the research questions. The mean score of the scale was ranged based on three levels (low, moderate, high). Findings reported that $6.34 \%$ of the participants scored low level of overall self-efficacy, $47.61 \%$ of the participants obtained a moderate level, and $46.05 \%$ fell into high level of self-efficacy. However, the mean score of the total self-efficacy for the whole sample $(\mathrm{M}=3.87, \mathrm{SD}=.590)$ obtained moderate level. Results in table 1 evidenced that participants scored good level of self-efficacy.

Table 1. Self-Efficacy level score

\begin{tabular}{cccc}
\hline \multicolumn{2}{c}{ Low } & Moderate & \multicolumn{2}{c}{ High } \\
less than $3 \%$ & 3 to $4 \%$ & \multicolumn{2}{c}{ Above $4 \%$} \\
$4 \quad 6.34$ & $30 \quad 47.61$ & & $29 \quad 46.05$ \\
$\begin{array}{c}\text { Mean Score of } \\
\text { the total Sample }\end{array}$ & \multicolumn{2}{c}{3.87,} & \multicolumn{2}{c}{$\begin{array}{c}\text { Standard } \\
\text { Deviation }=.590\end{array}$} \\
\hline
\end{tabular}

The differences levels of self-efficacy level based on the respondents' gender were performed through an independent sample t-test in order to compare the mean score of self-efficacy. The differences of self-efficacy level between male and female are shown in table 2 . The results revealed significant differences on the level of self-efficacy $(\mathrm{t}=2.838, \mathrm{df}=61$, sig. .006). More inspection on the gender levels results, the mean and standard deviation scores of self-efficacy showed that male participants displayed $(\mathrm{M}=4.05, \mathrm{SD}=.540)$ mean scores and female participants $(\mathrm{M}=3.65, \mathrm{SD}=.581)$.

Table 2. Results of independent sample t-test for self-efficacy

\begin{tabular}{cccc}
\hline Variable & $\mathrm{t}$ & $\mathrm{df}$ & Sig.2 tailed \\
\hline Self-Efficacy & 2.838 & 61 & .006 \\
\hline
\end{tabular}

The differences levels of self-efficacy level based on the respondents' age were performed through ANOVA test in order to compare the mean score of self-efficacy. The findings in table 3 presented insignificant difference levels of self-efficacy between students from different ages, $\mathrm{F}=1.435(.242 ; \mathrm{p}>0.05)$.

Table 3. ANOVA comparison age results on self-efficacy levels

\begin{tabular}{ccccc}
\hline Self-Efficacy & $\begin{array}{c}\text { Sum of } \\
\text { Squares }\end{array}$ & df & F & Sig. \\
\hline $\begin{array}{c}\text { Between } \\
\text { Groups }\end{array}$ & 1.469 & 3 & 1.435 & .242 \\
\hline Within Groups & 20.140 & 59 & .341 & \\
\hline Total & 21.609 & 62 & & \\
\hline
\end{tabular}

The differences levels of self-efficacy level based on the respondents' educational levels were performed through ANOVA test in order to compare the mean score of self-efficacy. The findings in table 4 presented insignificant difference levels of self-efficacy between students from different educational levels, $\mathrm{F}=1.859(.165 ; \mathrm{p}>$ $0.05)$.

Table 4. ANOVA results of self-efficacy based on educational level

\begin{tabular}{ccccc}
\hline Self-Efficacy & $\begin{array}{c}\text { Sum of } \\
\text { Squares }\end{array}$ & df & F & Sig. \\
\hline $\begin{array}{c}\text { Between } \\
\text { Groups }\end{array}$ & 1.261 & 2 & 1.859 & .165 \\
\hline Within Groups & 20.348 & 60 & & \\
\hline Total & 21.609 & 62 & & \\
\hline
\end{tabular}

\section{Discussion}

Based on the results of the study, self-efficacy level among university students was reported to be moderate. This can be attributed to students' positivity and their active participation as well as their own positive beliefs as they have the needed skills to deal with different situations. The results also may attribute to process guidance of the educational systems in which students followed the instruction of learning which linked the curriculum to the real life of students that helped control thinking processes and raise their belief in their abilities in general and self-efficacy in particular. The results also may attribute to the fact that the activities used in the learning-teaching process helped students develop self-confidence, which was reflected in their self-efficacy. The results also showed that there are statistically significant differences between the mean scores of the male and female students. It should be noted that recently involved in the education and work which lead to improve their self-efficacy levels and that would be gradually improved in both gender levels. Furthermore, many training sessions are organized in the educational environment and that would improve the personal, cognitive and social skills of both gender levels. The results also reported no significant differences on the level of self-efficacy based on participants' ages and their 
educational levels. The result may attribute to the availability of the training and workshops which helps people from different ages and educational levels to share their experiences and lead them to master gain several skills and that may play a crucial role in the insignificant differences results. Furthermore, the activities provided to all people are similar and encourage collaborations between the participants regardless their age and education levels, and that maximize their own expectations.

\subsection{Limitations and Recommendations}

Self-efficacy skills provide a tremendous space to enhance individual skills and potentials. More studies, especially ones based on empirical analysis, are needed to explore this space and predict its outcome. More research is needed to determine whether self-efficacy levels are linked to other variables. Furthermore, the behavioral and predictive results of individuals 'beliefs and academic performance must be taken into account. In another track, more research could be conducted to measure the quality-of- learning activities based on the quality of the learning environment. Another limitation is related to the small number of the study sample participants which limited the generalizability of the study result. Future studies should increase the number of participants. Finally, the method used in this study should be replaced with another data collection method such as qualitative and mix method to increase the validity of the results.

\subsection{Conclusion}

In conclusion, although few studies highlighted the importance of self-efficacy in the learning environment, researchers have not yet agreed on the effectiveness of academic and non-academic factors on personal and learning outcomes as few studies were conducted in the literature. Gonsalves [21] pointed out that learning approach is a key role in achieving significant self-efficacy and learner motivation. In other words, implementing learning approach fosters the learning of people and enhances their self-efficacy skills. Thus, in order to maximize the benefits of the learning activities, the study needs to know students' skills and abilities. Therefore, this study contributed to the literature on the self-efficacy construct.

\section{REFERENCES}

[1] Hutcherson C., Seppala E., J. Gross, "Loving-kindness mediation increases social connectedness," Emotion, vol. 8, no. 5, pp. 720-724, 2008.http://dx.doi.org/10.1037/a001323 7.

[2] Yusuf M, "The impact of self-efficacy, achievement motivation, and self-regulated learning strategies on students' academic achievement", Elsevier, vol. 15, no. 26, pp. 23-26, 2011. http://dx.doi.org/10.1016/j.sbspro.2011.04.158.

[3] Jdaitawi M, "Social connectedness, academic, non-academic behaviors related to self-regulation among university students in Saudi Arabia", International Journal Studies, vol. 8, no. 2, pp. 84-100, 2015. Jttp://dx.doi.org/10.5539/ies.v8n $2 \mathrm{p} 84$.

[4] Jdaitawi M, "The effect of using problem-based learning upon students emotions towards learning and levels of communication skills in three different disciplines", Croatian Journal of Education, vol. 22, no. 1, pp. 207-240, 2020. http://doi.org/10.15516/cje.v22i13215.

[5] Bandura A, "Self-efficacy mechanism in human agency," American Psychologist, vol. 37, no. 2, pp. 122-147, 1982.

[6] Bandura A, "Self-efficacy: Towards a unifying theory of behavioral change," Psychological Review, vol. 84, no. 2, pp. 191-215, 1977.

[7] Bandura A, "Self-efficacy: The exercise of control," W. H. Freeman: New York, USA, 1997.

[8] Carprara G., Fida R., Vecchione M., Bove G., Vecchio G., Barbaranelli C., A. Bandura, A, "Longitudinal Analysis of the Role of Perceived Self- Efficacy for Self- Regulated Learning in Academic Continuance an Achievement," Journal of Education Psychology, vol. 100, no. 3, pp. 525-534, 2008.

[9] Zajacova A., Lynch S., J. Espenshade, "Self-Efficacy, Stress, Academic Success in College," Research in Higher Education, vol. 46, no. 6, pp. 677-706, 2005.

[10] Melih T, "Academic Self-Efficacy Beliefs of Undergraduate Mathematics Education Student," Acta Didactica Napocensia, vol. 6, no. 1, pp. 33-39, 2013.

[11] Zamfir A., C, Mocaanu, "Perceived academic self-efficacy among Romanian upper secondary education students" International Journal of Environmental Research and Public Health, vol. 17, pp. 4689, 2020. http://doi:10.3390/ijerph17 134689 .

[12] Ramadan A, "Spatial ability and its measure, development and effectiveness on secondary school student's metacognition skills". Unpublished Doctoral Dissertation. Institutions of Educational Studies and Research, Egypt, 2005.

[13] Esterly E. et al. "A Multi-Method Exploration of The Mathematics Teaching Efficacy and Epistemological Beliefs of Elementary Preservice and Novoice Teachers" Dissertation, Ohio State University, 2003.

[14] Zimmerman B, "Self-Efficacy: An Essential Motive to Learn", Contemporary Educational Psychology, vol. 25, no. 1, pp. 82-91, 2000.

[15] Migdadi A, "The effectiveness of training program based on emotional-mental education in enhancing social efficacy and solving problem skills among 7th and 8th grade students," Islamic University Journal, Dirasat Series, vol. 18, no. 2, pp. 521-555, 2010.

[16] Abo-Ghali A, "The effectiveness of self and its relationships to life stressors among married female students in Al-Aqsa University," Islamic University Journal of Psychological and Educational Studies, vol. 20, no. 1, pp. 619-654, 2012. 
[17] Jdaitawi M, "Does flipped learning promote positive emotions in science education? A comparison between traditional and flipped classroom approaches," Electronic Journal of e-Learning, vol. 18, no. 6, pp. 516-524, 2020. DOI:10.34190/JEL.18.6.004.

[18] Jdaitawi M, "Students perspectives on university experiences, the role of protective factors in students lives. International Education Studies, vol. 6, no. 7, pp. 236-249, 2013. http://dx.doi.org/10.5539/ies.v6n7p239.

[19] Li H., Bi R., Q, Zhong, "The development and psychometric testing of a disaster response self-efficacy scale among undergraduate nursing students," Nurse Education Today, vol. 59, pp. 16-20, 2017.

[20] Öztekin S. Larson E., Yüksel S., G. Altun Uğraş, "Undergraduate nursing students' perceptions about disaster preparedness and response in Istanbul, Turkey, and Miyazaki, Japan: A cross-sectional study: UNS perceptions on DP\&R," Japan Journal of Nursing Science, vol. 12, no. 2, pp. 145-153, 2015.

[21] Gonsalves J., Metchik E., Lynch C., Belzos C., P. Richards," Optimizing service-learning for self-efficacy and learner empowerment, " Michigan Journal of Community Service Learning, vol. 25, no. 1, 2019. 